\title{
I can grow as an in utero if you give me enough nutrition: premature $\leq 29$ weeks gestation
}

Authors: Angela B. Hoyos ${ }^{1}$

1. Neonatology, Clinica del Country, Bogota, DC, Colombia. Professor of Pediatrics, Bosque University, Bogotá, Colombia.

https://orcid.org/0000-0002-5403-3268

\section{Abstract}

Introduction: In general, everyone believe they should grow as "in utero" for the smallest premature babies but many thinks that it is not possible with today's nutrition "guidelines". There is resistance to give enough nutrition for fear of "toxicity". We use volumes that some would consider high, although there are more and more groups that accept it. We chose the difference in Z-score between birth and a corrected discharge gestational age to assess postnatal growth in our unit.

Material and methods: Between January 2018 and December 2020, we review all cases $\leq 29$ weeks of GA at birth that survived to 36 weeks corrected gestational age, or that were discharged home if this occurred before. We had a protocol with extremely aggressive nutrition including parenteral as well as oral nutrition. We then separated the patients who had lost more than $1 \mathrm{Z}$ score point to see the weight trajectory plotted on the Fenton 2013 growth curve and to review the clinical characteristics of those patients. We also graphed the patients who had had a smaller Z-score difference to also see their trajectory in the Fenton curves. We calculate the number of cases, medians, and interquartile ranges for all groups.

Results: We found 32 cases. The median \pm IQR (interquartile range) of change in Z-score between birth and discharge of the whole group was $-0.52 \pm 0.53 ; 6 / 32$ (19\%) had more than 1 point drop; all had severe diseases listed in Figure 1 with plotting all cases. The median decline in Z score \pm IQR of this group with poor growth was $-1.24 \pm 0.22$. The group of cases with a fall of $<1$ point of $Z$ score were $26(81 \%)$, the median \pm IQR of fall of $Z$ score was $-0.39 \pm 0.55$ (see figure 2 ). All cases had the initial fall in weight the first 1-2 weeks. No important complications secondary to the ingested volumes or parenteral nutrition were reported.

Conclusion: The group of cases with a fall of $>1$ point of $Z$ score had severe pathologies. The other cases had an adequate growth parallel to normal growth charts in some cases with some catch up.

Discussion: With this work we try to show that in many premature babies it is possible to grow like in utero if they are given enough nutrition. Randomized studies are necessary to confirm our findings.

Key words: Very premature infants, Z-score on weight, nutrition, appropriate growth 


\section{Introduction}

There is a wide variety of nutrition concepts in newborn units around the world. In general, everyone believe they should grow as "in utero" for the smallest premature babies(1) but many thinks that it is not possible with today's nutrition "guidelines"(2). There is resistance to give enough nutrition for fear of "toxicity" especially in parenteral nutrition,(3-5) spatially protein and lipids. Fear of volume overload after 2 weeks of life is also a limitation because "bronchopulmonary dysplasia" can occur, although it has not been proven to be due to the feeding volume(6). Furthermore, there is fear of overfeeding these premature infants with the consequent "excess adiposity"(7) and adult diseases. With regard to adiposity, Dr. Lingwood et al. showed that this adiposity is associated with poor nutrition intake in the first two weeks of life, including lipids, and not with excess nutrition.(8)

It would take a long time to discuss all the arguments for and against these assertions because they are all based on some reality that is often distorted and out of context. However, no one has shown that it is harmful to give enough nutrition to grow as in utero before 36 weeks gestational age (GA). On the other hand, there is sufficient evidence that poor nutrition and poor growth have serious adverse consequences.(1, 9-12)

For many years, in several units where I have worked and directed, we use volumes that some would consider high, although there are more and more groups that accept it.(13-15) This principle was based on the observation of many years ago when we had premature babies until they reached more than 2,500 grams to be put up for adoption. When we allowed free demand, these premature babies ingested between 200 and $300 \mathrm{~mL} / \mathrm{kg} /$ day and occasionally more. After weighing benefits versus risks, we concluded that we should reach at least $200 \mathrm{~mL} / \mathrm{K} /$ day after the initial stage when growth began, and we had already passed the basic problems of the first weeks. Also, our concept of parenteral nutrition has been modified, starting earlier and with higher quantity of macronutrients, concentrating nutrition to limit the initial volume. In recent years we have noticed in EpicLatino reports (16), the Latin American database, that our unit has much better nutrition results than almost all the others. The aim of this work is to review the nutrition results of our small premature infants since 2018 when we set up minimal handling protocol to prevent intraventricular hemorrhage.

The $\mathrm{Z}$ score represents the distance from the 50th percentile of a growth curve, with " 0 " being the 50th percentile, negative numbers if they are below and positive if they are above. The $Z$ score allows mathematical calculations while the percentiles do not. We chose the difference in Z-score between birth and a specific gestational age because birth weight is the reality of each patient that cannot be modified, and we want to know what growth occurred afterwards.

\section{Material and methods}

In late 2017 we began a protocol of minimal handling to prevent intraventricular hemorrhage in $\leq$ 30 weeks gestation that included high parameters of parenteral nutrition and initiation of oral feeds on the first day of life that we have kept until today. 
Nutrition protocol in our unit:

1. Parenteral fluids are started by central catheter with a mixture of $3 \%$ amino acids and $10 \%$ dextrose until it is possible to prepare personalized parenteral nutrition (within the next $24-36$ hours) at an infusion of $70 \mathrm{~mL} / \mathrm{Kg} / \mathrm{day}$, humidity at $80 \%$ and minimal handling. This amount is not increased if diuresis remains adequate $(>1 \mathrm{~mL} / \mathrm{K} / \mathrm{hour})$.

2. Parenteral nutrition is calculated with the following parameters:

$>$ Protein at $4 \mathrm{gr} / \mathrm{Kg} / \mathrm{day}$

$>$ Lipids at $3 \mathrm{gr} / \mathrm{Kg} /$ day

$>$ Glucose $4 \mathrm{mg} / \mathrm{Kg} /$ minute

$>$ Vitamins, calcium, phosphorus, magnesium (after the 3rd day) and trace elements. These parameters are not changed for 3 days and parenteral nutrition is concentrated to about $80 \mathrm{~mL} / \mathrm{kg} /$ day.

3. Enteral nutrition is started in the first 24 hours with premature formula (we do not have bank milk) 1-3 mL/Kg/every 3 hours (approx. 10-20 mL/Kg/day) until we have milk from the mother; this is continued for 3 days.

4. From the $3 \mathrm{rd}$ day we increase oral nutrition and decrease parenteral nutrition to maintain approximately $4 \mathrm{~g} / \mathrm{Kg} /$ day of protein, assuming a fecal loss of around $15-20 \%$ and understanding that the digestible and usable protein of breast milk that is used for growth it is only 1-1.5 gr/K/day before fortifying, especially after the second week.(17-19) As soon as we managed to get the mother to produce enough breast milk, we fortified it with fortifiers of bovine origin since we do not have any other type. The increase is made by 20$40 \mathrm{mg} / \mathrm{Kg} /$ day according to tolerance until reaching $200 \mathrm{~mL} / \mathrm{Kg} /$ day. Each patient is graphed on Fenton curves and it is occasionally necessary to increase this nutrition due to poor growth.

5. At around 35-36 weeks corrected gestational age, if the patient has grown adequately, we discontinue fortification or preterm formula. Often at this gestational age they are discharged.

To see how our premature babies grow as of January 1, 2018, we decided to review all cases $\leq$ 29 weeks of GA at birth that survived to 36 weeks corrected gestational age, or that were discharged home if this occurred before. We calculated the $Z$ score at birth using the 2013 Fenton curves and at discharge to see the difference and we also calculated the $Z$ score at 36 weeks corrected age and at discharge in premature infants who had not gone home at the corrected gestational age of 36 weeks.

We then separated the patients who had lost more than 1 Z-score point to see the weight trajectory plotted on the Fenton 2013 growth curve and to review the clinical characteristics of those patients. We also graphed the patients who had had a smaller Z-score difference to also see their trajectory in the Fenton curves. We calculate the number of cases, medians, and interquartile ranges for all groups.

Results

The total number of cases born $\leq 29$ weeks of GA between January 2018 and December 2020 that survived 36 weeks or discharge home was 32 . The median \pm IQR (interquartile range) of change in $Z$-score between birth and discharge of the whole group was $-0.52 \pm 0.53$. Six patients had a 
change in $Z$ score between birth and discharge of more than 1 point (19\%) including 1 case that had a difference of 2.2; all had severe diseases listed in Figure 1. We plotted these cases. The median decline in $Z$ score \pm IQR of this group with poor growth was $-1.24 \pm 0.22$. All preterm infants at discharge who had more than 1 point difference in the Z-score already had it at 36 weeks corrected age.

The group of cases with a fall of $<1$ point of $Z$ score were $26(81 \%)$, the median \pm IQR of fall of $Z$ score was $-0.39 \pm 0.55$ (see figure 2 )

All cases had the initial fall in weight the first 1-2 weeks. No complications secondary to the ingested volumes were reported, diuretics were not used in any of the cases, and parenteral nutrition was adequately tolerated except for an occasional hyperglycemia that was corrected by reducing glucose intake.

\section{Conclusions}

The initial drop in weight due to volume contraction that occurs in all patients and is clearly considered physiological and desirable in the fluid literature(20) was observed in all cases. However, it should only be a volume contraction and not a sum of malnutrition added due to poor nutrition that is very frequent in the units for "fear" of toxicity, especially parenteral nutrition. Growth as in utero should be measured from nadir, but since nutrition is often unknown in the first week, it is measured from birth and a slight drop is accepted as normal. This drop was small in $81 \%$ of all cases but was greater in a group of patients (19\%) who had serious illnesses.

It is interesting to note that acute pathologies during hospital stay such as NEC (necrotizing enterocolitis) growth decelerates for a period and then accelerates again, but of course it never manages to compensate for this drop as seen in figure 1. Other pathologies (although is a single case) as BPD (bronchopulmonary dysplasia) have the latest growth deceleration, probably when we try to get the patient to get enough nutrients to go home or due to corticosteroids. On the other hand, the pathologies that probably have their origin in intrauterine life, their growth slows evenly.

Most cases 26/32 (81\%) have adequate growth, approaching the birth percentile but often not reaching it. However, the growth after the weight nadir is parallel to the growth curves as seen in figure 2 which for us is to grow as in utero. 


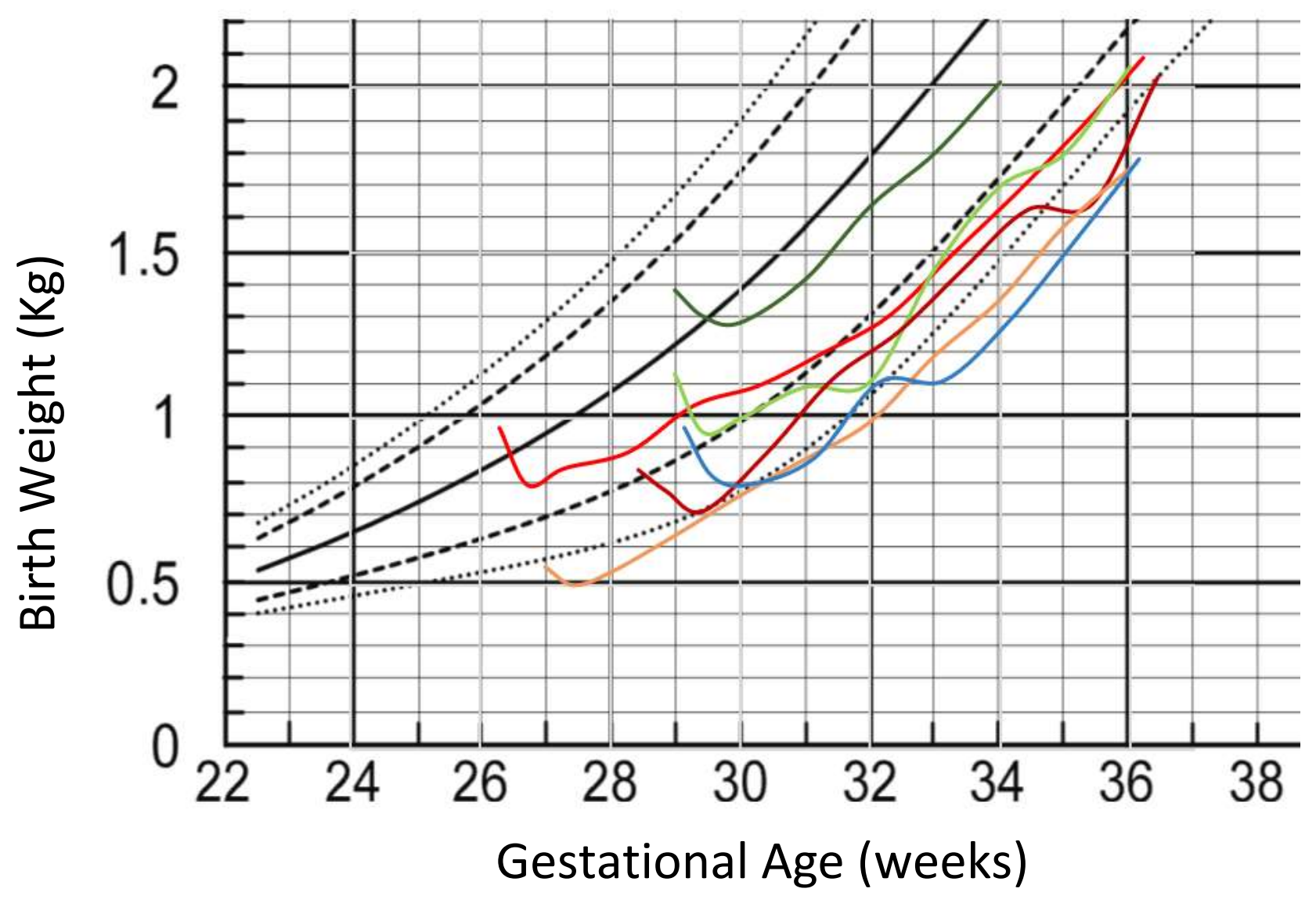

Suspected primary immunodeficiency

Death 2nd twin

NEC

Severe bronchopulmonary dysplasia

Severe CMV disease

NEC

Figure 1: Growth graph curves of six preterm infants (19\%) whose Z-scores between birth and discharge fell more than 1 point and their underlying pathology plotted on the 2013 Fenton curves up to 36 weeks of corrected age or discharge. NEC: necrotising enterocolitis, CMV:

cytomegalovirus. 


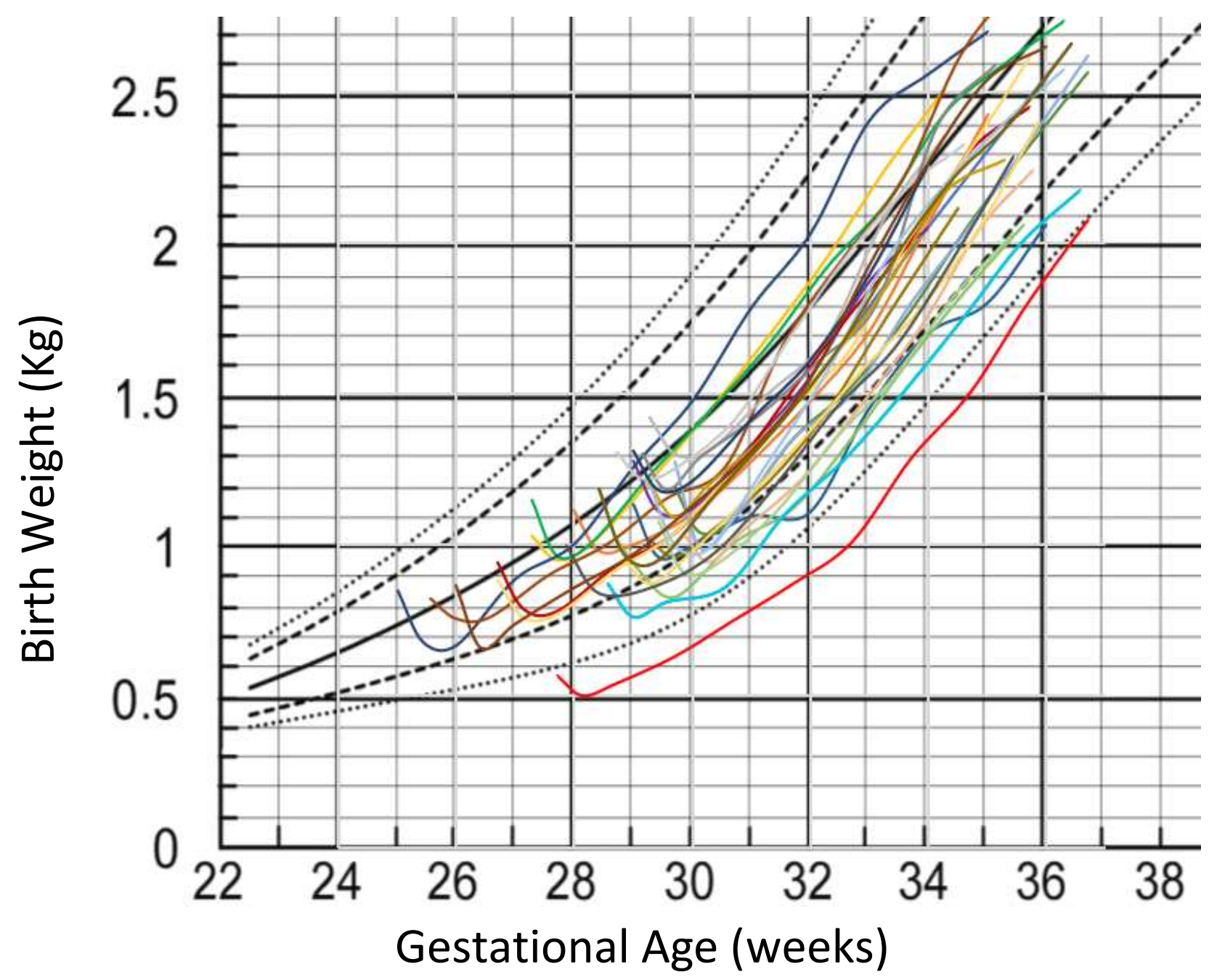

Figure 2: The rest of patients (81\%) graphed according to their growth curve (Fenton 2013). Note the initial drop during volume contraction with the subsequent increase parallel to the growth curves. Some reach 36 weeks near their birth percentile.

\section{Discussion}

There are no universally accepted postnatal nutrition standards during their unit stay in the smallest preterm infants, but there is a universal consensus to grow as in utero as discussed in the introduction. Fear of toxicity has limited the amount of nutrients used in many units. With this work we try to show that in many premature babies it is possible to grow like in utero if they are given enough nutrition. Our strength is that we have been administering aggressive nutrition without complications for several years, but as a limitation it is a retrospective observational small study that does not control the variables and has no power to rule out complications. Randomized studies are necessary to confirm our findings. 


\section{References}

1. Hay WW. Nutritional Support Strategies for the Preterm Infant in the Neonatal Intensive Care Unit. Pediatr Gastroenterol Hepatol Nutr. 2018;21(4):234-47.

2. Kim MJ. Enteral nutrition for optimal growth in preterm infants. Korean J Pediatr. 2016;59(12):466-70.

3. Taylor S, editor Addressing the Persistent Controversies and Questions in Preterm Infant Nutrition: Translating the Pre-B Project Into Clinical Practice and a Research Agenda. PAS 2021; 2021 Tuesday, May 4, 2021, 1:00 PM - 3:00 PM US CT; Virtual.

4. van Goudoever JB, Carnielli V, Darmaun D, Sainz de Pipaon M, nutrition EEECwgopp. ESPGHAN/ESPEN/ESPR/CSPEN guidelines on pediatric parenteral nutrition: Amino acids. Clin Nutr. 2018;37(6 Pt B):2315-23.

5. Mihatsch W, Shamir R, van Goudoever JB, Fewtrell M, Lapillonne A, Lohner S, et al. ESPGHAN/ESPEN/ESPR/CSPEN guidelines on pediatric parenteral nutrition: Guideline development process for the updated guidelines. Clin Nutr. 2018;37(6 Pt B):2306-8.

6. Barrington KJ, Fortin-Pellerin E, Pennaforte T. Fluid restriction for treatment of preterm infants with chronic lung disease. Cochrane Database Syst Rev. 2017;2:CD005389.

7. Uthaya S, Thomas EL, Hamilton G, Doré CJ, Bell J, Modi N. Altered adiposity after extremely preterm birth. Pediatr Res. 2005;57(2):211-5.

8. Lingwood BE, Al-Theyab N, Eiby YA, Colditz PB, Donovan TJ. Body composition in very preterm infants before discharge is associated with macronutrient intake. $\mathrm{Br} J$ Nutr. 2020;123(7):800-6.

9. Nosarti C, Al-Asady MH, Frangou S, Stewart AL, Rifkin L, Murray RM. Adolescents who were born very preterm have decreased brain volumes. Brain. 2002;125(Pt 7):1616-23.

10. Moster D, Lie RT, Markestad T. Long-term medical and social consequences of preterm birth. N Engl J Med. 2008;359(3):262-73.

11. Rotteveel J, van Weissenbruch MM, Twisk JW, Delemarre-Van de Waal HA. Infant and childhood growth patterns, insulin sensitivity, and blood pressure in prematurely born young adults. Pediatrics. 2008;122(2):313-21.

12. Rossi P, Tauzin L, Marchand E, Boussuges A, Gaudart J, Frances Y. Respective roles of preterm birth and fetal growth restriction in blood pressure and arterial stiffness in adolescence. $J$ Adolesc Health. 2011;48(5):520-2.

13. Abiramalatha $\mathrm{T}$, Thomas $\mathrm{N}$, Thanigainathan $\mathrm{S}$. High versus standard volume enteral feeds to promote growth in preterm or low birth weight infants. Cochrane Database Syst Rev. 2021;3:CD012413.

14. Thomas N, Cherian A, Santhanam S, Jana AK. A randomized control trial comparing two enteral feeding volumes in very low birth weight babies. J Trop Pediatr. 2012;58(1):55-8.

15. Kuschel CA, Evans N, Askie L, Bredemeyer S, Nash J, Polverino J. A randomized trial of enteral feeding volumes in infants born before 30 weeks' gestation. J Paediatr Child Health. 2000;36(6):581-6.

16. EpicLatino. Epiclatino Repport 2019. https://www.epiclatino.co/report-2019; 2019.

17. Lönnerdal B, Erdmann P, Thakkar SK, Sauser J, Destaillats F. Longitudinal evolution of true protein, amino acids and bioactive proteins in breast milk: a developmental perspective. J Nutr Biochem. 2017;41:1-11.

18. Haschke F, Haiden N, Thakkar SK. Nutritive and Bioactive Proteins in Breastmilk. Ann Nutr Metab. 2016;69 Suppl 2:17-26.

19. Boniglia C, Carratù B, Chiarotti F, Giammarioli S, Sanzini E. Influence of maternal protein intake on nitrogen fractions of human milk. Int J Vitam Nutr Res. 2003;73(6):447-52. 
20. Selewski DT, Gist KM, Nathan AT, Goldstein SL, Boohaker L, Akcan-Arikan A, et al. The impact of fluid balance on outcomes in premature neonates: a report from the AWAKEN study group. Pediatr Res. 2020;87(3):550-7. 